\title{
Adverse Event Unexpected Reason Code
}

National Cancer Institute

\section{Source}

National Cancer Institute. Adverse Event Unexpected Reason Code. NCI Thesaurus. Code C93723.

A coded value specifying the representation of the criteria for determining whether an adverse event (experience or reaction) is considered unanticipated. 